\title{
TECNOLOGIAS SOCIAIS
}

Tecnologias sociais podem ser definidas como um método ou instrumento capaz de solucionar algum tipo de problema social e que atenda aos quesitos de simplicidade, baixo custo, fácil aplicabilidade e geração de impacto social. Esse tipo de tecnologia se origina de um processo de inovação resultante do conhecimento criado coletivamente pelos atores interessados no seu emprego. Em um contexto político e social em que emergem interesses na elaboração de políticas sociais inclusivas, os processos, técnicas e metodologias desenvolvidos na interação com a população representam uma alternativa para facilitar a inclusão social e a melhoria na qualidade de vida. Tania P. Christopoulos, professora da EACH/USP, pesquisa esse tema há mais de sete anos e oferece indicações que podem auxiliar na compreensão do tema.
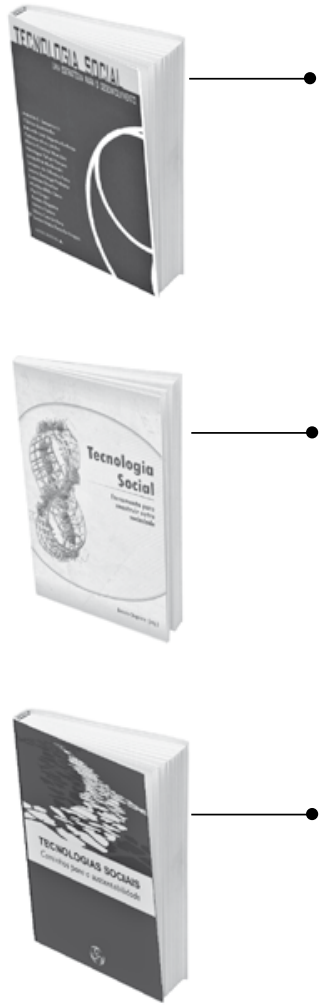

TECNOLOGIAS SOCIAIS: Caminhos para a sustentabilidade. Aldalice Otterloo e outros. Brasília: Rede de Tecnologia Social, 2009.

Coletânea de artigos de membros integrantes da RTS. Os textos são produtos de reflexões sobre o papel das Tecnologias Sociais para o desenvolvimento do país, de acordo com as peculiaridades e potencialidades de cada região, e sobre as maneiras como distintos atores podem se articular por meio de TS, criando uma plataforma comum de ações.

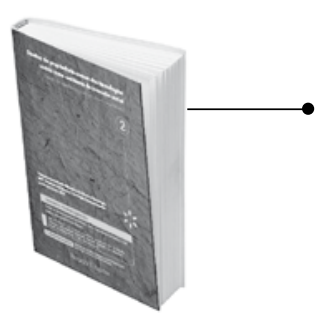

DIREITOS DE PROPRIEDADE COMUM DAS TECNOLOGIAS SOCIAIS COMO AMBIENTE DE INOVAÇÃO SOCIAL. Ricardo T. Neder. Brasília: UnB, 2009.

O autor analisa como o marco regulatório de Ciência, Tecnologia e Inovação vigente afeta as inovações e tecnologias sociais e as políticas públicas a elas subjacentes. São avaliadas as condições necessárias para que os recursos destinados às políticas de inovação empresarial possam ser igualmente viabilizados para ambientes de políticas públicas de desenvolvimento e inclusão social, por meio de uma regulamentação adequada da política de Ciência, Tecnologia e Inovação.

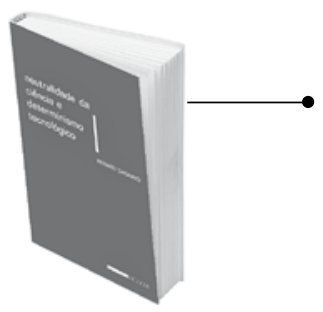

NEUTRALIDADE DA CIÊNCIA E DETERMINISMO TECNOLÓGICO. Um debate sobre a tecnociência. Renato Dagnino. Campinas: Unicamp, 2008.

O debate que este livro promove é referente à possibilidade de se construir um estilo de desenvolvimento socialmente justo e economicamente viável sobre estruturas distintas das concebidas pela visão cognitiva tecnológico-científica fundada nos valores e interesses prevalecentes da sociedade que se planeja transformar. 